\title{
ESTRATÉGIAS DE GESTÃO DA EDUCAÇÃO E EQUIDADE: O CASO DO PROGRAMA APRENDIZAGEM NA IDADE CERTA (MAIS PAIC) ${ }^{1}$
}

\author{
ESTRATEGIAS DE GESTIÓN DE LA EDUCACIÓN Y EQUIDAD: EL CASO DEL \\ PROGRAMA APRENDIZAGEM NA IDADE CERTA (MAIS PAIC)
}

\section{EDUCATION MANAGEMENT STRATEGIES AND EQUITY: THE CASE OF THE PROGRAM 'LITERACY AT THE RIGHT AGE' (MAIS PAIC)}

\author{
Maria do Carmo Meirelles Toledo CRUZ ${ }^{2}$ \\ Marta Ferreira Santos FARAH ${ }^{3}$ \\ Vanda Mendes RIBEIRO ${ }^{4}$
}

RESUMO: O artigo visa apresentar as estratégias de gestão do Programa Alfabetização na Idade Certa (Paic), uma política educacional implementada no estado do Ceará desde 2007 e que, segundo pesquisas, tem ampliado a equidade educacional. $O$ estudo fez uso de referências bibliográficas e de entrevistas com gestores da Secretaria Educacional do Estado e professores de Fortaleza. Conclui-se que as principais estratégias de gestão adotadas nos 13 anos do Programa foram a reordenação da Secretaria, com a criação de um departamento dedicado à cooperação com os municípios; a adoção de eixos que organiza a ação do Paic em cascata, partindo da Secretaria até chegar às escolas; a adoção de instrumentos e ferramentas que colocam os agentes implementadores em torno de objetivos comuns; a ação sistêmica; o acompanhamento e o monitoramento das ações e dos resultados, com divulgação dos avanços; e a mobilização dos municípios e outros atores sociais.

PALAVRAS-CHAVE: Políticas públicas em educação. Equidade. Alfabetização. Paic. Gestão educacional.

\footnotetext{
${ }^{1} \mathrm{O}$ presente trabalho origina-se na tese de doutorado de uma das autoras, realizada com apoio da Coordenação de Aperfeiçoamento de Pessoal de Nível Superior - Brasil (Capes), código de financiamento 001, e do GV Pesquisa da Escola de Administração de Empresas de São Paulo da Fundação Getulio Vargas (EAESP-FGV). Versão original deste foi apresentado em projeto da Fundação Tide Setúbal, que visou sistematizar iniciativas de gestão da educação básica nacional que conseguiram, segundo pesquisas publicadas, incidir sobre a desigualdade educacional, melhorando os níveis de aprendizagem de todos os alunos e, ampliando assim, a equidade. $\mathrm{O}$ texto originário deste artigo encontra-se no PortalIdea, desenvolvido pela referida Fundação (https://portalidea.org.br/inspirese/). Na formulação do texto, foram também utilizados dados coletados no âmbito da pesquisa Implementação de Políticas Educacionais e Equidade em Contextos de Vulnerabilidade Social, que conta com a participação de duas das autoras e que é financiada pela Fundação de Amparo à Pesquisa do Estado de São Paulo (Processo Fapesp: 2018/11257-6).

${ }^{2}$ Universidade da Cidade de São Paulo (UNICID), São Paulo - SP - Brasil. Professora no Programa de Pósgraduação em Educação. Doutorado em Administração Pública e Governo (FGV-SP). ORCID: https://orcid.org/0000-0003-4375-5270. E-mail: carminhameirelles@gmail.com

${ }^{3}$ Fundação Getúlio Vargas (FGV), São Paulo - SP - Brasil. Professora dos cursos de Graduação e de Pósgraduação stricto sensu em Administração Pública e Governo. Doutorado em Sociologia (USP). ORCID: https://orcid.org/0000-0002-6517-3004. E-mail: marta.farah@fgv.br

${ }^{4}$ Universidade da Cidade de São Paulo (UNICID), São Paulo - SP - Brasil. Professora no Programa de Pósgraduação em Educação. Doutorado em Educação (USP). ORCID: https://orcid.org/0000-0002-2275-7122. Email: vandaribeiro2@gmail.com
}

RPGE- Revista on line de Política e Gestão Educacional, Araraquara, v. 24, n. 3, p. 1286-1311, set./dez. 2020. e-ISSN:1519-9029. DOI: https://doi.org/10.22633/rpge.v24i3.13904 
RESUMEN: El artículo tiene como objetivo presentar las estrategias de gestión del Programa de Alfabetización en la Edad Adecuada (Paic), una política educativa implementada en Ceará desde 2007 y que a partir de la investigación mostró que ha aumentado la equidad educativa. El estudio utilizó referencias bibliográficas y entrevistas con gerentes de la Secretaría de Educación del Estado y maestros de Fortaleza. Se concluyó que las principales estrategias de gestión adoptadas en los 13 años del Programa fueron: la reorganización de la Secretaría, con la creación de un departamento dedicado a la cooperación con los municipios; la adopción de ejes que organizan la acción de Paic en cascada, desde la Secretaría hasta las escuelas; la adopción de instrumentos y herramientas que ubican a los agentes implementadores en torno a objetivos comunes; la acción sistémica; el seguimiento y monitoreo de acciones y resultados, con la difusión del progreso; y la movilización de municipios y otros actores sociales.

PALABRAS CLAVE: Políticas públicas en educación. Equidad. Alfabetización. Paic. Gestión educativa.

ABSTRACT: The aim of the current article is to present the management strategies of the 'Literacy at the Right Age' Program (Paic - Programa Alfabetização na Idade Certa). This educational policy was implemented in Ceará State in 2007; according to different studies, it helped increasing educational equity. Data collection methodology was based on bibliographic references and on interviews conducted with managers of the State Educational Secretariat and with teachers who worked in the City of Fortaleza. The main management strategies adopted in 13 years of Program lied on reorganizing the Secretariat by creating a department focused on enabling its cooperation with different municipalities; on adopting axes capable of organizing Paic's action in cascade, starting from the Secretariat until reaching schools; on adopting instruments and tools to enable implementing agents to focus on common goals; on implementing systemic actions; on following-up and monitoring actions and results, with subsequent progress disclosure; as well as on mobilizing municipalities and several social actors.

KEYWORDS: Public educational policies. Equity. Literacy. Paic. Educational management.

\section{Introdução}

O presente artigo tem como objetivo central apresentar as estratégias de gestão do Programa Aprendizagem na Idade Certa (Mais Paic), uma iniciativa que, segundo pesquisas, conseguiu ampliar a equidade educacional nos anos iniciais do ensino fundamental.

O conceito de equidade aqui apresentado, parte do entendimento de que a distribuição dos bens públicos educacionais deveria favorecer a população mais vulnerável (DUBET, 2009) e promover a justiça social. A equidade "supõe um princípio capaz de corrigir desigualdades em favor de quem tem menos na distribuição dos bens sociais” (RIBEIRO, 2014, p. 1102). Considerando esses autores, o conceito de equidade utilizado neste texto, enquanto princípio de justiça, prevê que uma política educacional deveria promover níveis 
adequados de desempenho a todas as crianças, com destaque para aquelas que possuem menor nível socioeconômico.

A equidade na educação, nos termos acima mencionados, não é um resultado fácil de ser alcançado. Nos anos 60, a Sociologia da Educação demonstrou que há correlação entre o nível socioeconômico das famílias e o desempenho acadêmico dos alunos (COLEMAN et al., 1966; BOURDIEU; PASSERON, 1975). Desde então, as pesquisas, mesmo aquelas que apontam outros fatores intervenientes no desempenho dos alunos, não deixaram de reconhecer o nível socioeconômico como o mais forte preditor da desigualdade escolar (BROOKE; SOARES, 2008). Produzir equidade educacional implica em incidir, de algum modo, sobre a referida correlação. O Paic tem conseguido contribuir para a ampliação da equidade nos anos iniciais do ensino fundamental, diminuindo a distância no desempenho dos alunos que vivem em localidades menos e mais pobres (PADILHA et al., 2008) ou que são de escolas com mais e menos famílias com menor nível socioeconômico (KASMIRSKI; GUSMÃO; RIBEIRO, 2017).

O Programa Alfabetização na Idade Certa (Paic) foi criado em 2007 pelo governo cearense com o objetivo de promover a alfabetização de todas as crianças da rede pública cearense, com foco no $2^{\circ}$ ano do ensino fundamental (EF). Segundo documentos e entrevistas, o Paic buscou criar uma cultura institucional voltada à aprendizagem do aluno e à mudança das gestões municipal e escolar (CEARÁ, 2012; CRUZ, 2007). A Secretaria da Educação (Seduc) coordena a política, que tem a finalidade de reduzir desigualdades e ampliar o acesso à educação, e coopera técnica e financeiramente com os municípios para que efetivem a política de educação por meio de programas e assistência técnica (SEGATTO, 2015).

O Paic tem como origem a experiência implementada na educação em Sobral que, a partir de 2000, passou a realizar ações para garantir o direito à alfabetização e a universalização do acesso. Essas ações tiverem início após a identificação, por meio de uma avaliação diagnóstica, de que a maioria das crianças, após 2 ou 3 anos de matrícula nas escolas públicas do munício, não sabiam ler. De 2001 a 2004, Sobral matriculou todas as crianças de 7 anos no EF; reduziu a taxa de distorção idade-série, nos anos iniciais do EF, de 28,5 para 13,6; e a taxa de abandono, de 3,8 para 0,7 (INEP, 2005). O trabalho foi organizado a partir de "frentes estratégicas" com atuações em gestão institucional, fortalecimento da gestão escola, fortalecimento da ação pedagógica e valorização do magistério, mas com a visão que todas as crianças “poderiam aprender” (SUMIYA, 2019).

Esta experiência foi levada à Assembleia Legislativa do estado quando o secretário municipal de educação de Sobral foi eleito deputado estadual para o mandato de 2003 a 2006 
com a bandeira de melhoria da educação. Em 2004, organizou o Comitê Cearense para a Eliminação do Analfabetismo Escolar, coordenado pela Assembleia, com ao apoio do Fundo das Nações Unidas para a Infância (Unicef), da Associação dos Municípios e Prefeitos do Estado do Ceará (Aprece), da União dos Dirigentes Municipais de Educação do Ceará (Undime), do Instituto Nacional de Estudos e Pesquisas Educacionais Anísio Teixeira (Inep) e das universidades Estadual do Ceará (UEC), Federal do Ceará (UFC), Estadual do Vale do Acaraú (UVA), Regional do Cariri (Urca) e de Fortaleza (Unifor) (CEARÁ, 2016a). As ações do Comitê tiveram como base a avaliação nacional de 2001 e uma avaliação amostral dos estágios de aprendizagem de leitura, escrita e compreensão de texto de alunos da 2a série do EF (atual $3^{\circ}$ ano) e os resultados apontaram que apenas $15 \%$ leram e compreenderam o texto (GUSMÃO; RIBEIRO, 2011; CEARÁ, 2016a). Outras pesquisas também contribuíram com este diagnóstico do analfabetismo no estado que identificavam que a grade curricular da maioria das universidades cearenses não promovia a formação de professor alfabetizador e era preciso aprimorar os mecanismos utilizados pelos docentes para alfabetizar as crianças (CRUZ, 2019).

$\mathrm{O}$ analfabetismo escolar no estado passou a ser enfrentado por meio de um pacto entre os diversos atores, para garantir o direito de todas as crianças serem alfabetizadas até 7 anos. Assim, surgiu o Paic em 2005, ainda como iniciativa não governamental, com o objetivo de “apoiar os municípios cearenses na melhoria da qualidade do ensino, da leitura e da escrita nos anos iniciais do ensino fundamental" (CEARÁ, 2016a). Esta ação contou com a parceria da Aprece, Undime e do Unicef e foi organizado a partir de um projeto-piloto, realizado de 2005 a 2006, com 56 municípios (GUSMÃO; RIBEIRO, 2011). No decorrer de sua implementação, várias estratégias de comunicação foram adotadas para divulgar os resultados da desigualdade de aprendizagem aos municípios e à sociedade civil, visando a mobilização pelo direito à aprendizagem de todos e a necessidade de ampliar a capacidade institucional dos municípios e formar os professores de todos os municípios, com vistas à redução das desigualdades regionais e intramunicipais.

Em 2007, quando o governador Cid Gomes, ex-prefeito de Sobral, assumiu o governo do estado, transformou o Paic em uma política pública, com o apoio da Undime, UFC e do Unicef. Havia ainda um contexto favorável à implementação do Paic em função de ações desempenhadas por secretários estaduais de educação desde 1995 como profissionalização das equipes, ao fortalecimento do regime de colaboração com os municípios, acompanhamento e avaliação de resultados (NASPOLINI, 2001; VIEIRA; PLANK; VIDAL, 2019). 
Para a sua implementação, gestores e técnicos do município de Sobral passaram a integrar cargos da Secretaria da Educação do Estado do Ceará (Seduc). A experiência sobralense contribuiu para sua formulação e o programa foi institucionalizado por meio da Lei 14.026/2007 (SUMIYA, 2019).

A política educacional do Estado passou a priorizar, no processo de cooperação com os municípios a alfabetização na idade certa. Desde sua criação, o Paic tem sido reformulado constantemente e, em 2011, ampliou o atendimento até o $5^{\circ}$ ano do EF, sendo a partir de então denominado Paic +5 . Novas ações de aprendizagem passaram a ser desenvolvidas para a Matemática. Em 2015, o Estado iniciou o desenho da expansão das iniciativas para o $9^{\circ}$ ano, envolvendo também a disciplina de Ciências. Nesse momento, o Programa foi denominado como Programa de Aprendizagem na Idade Certa (Mais Paic). Os resultados do Paic levaram o governo federal, em 2012, a disseminar um Programa nele inspirado, o Pacto Nacional pela Alfabetização na Idade Certa (Pnaic).

Para a elaboração deste artigo foi empregada abordagem qualitativa de pesquisa. Os procedimentos metodológicos foram desenvolvidos em duas etapas. Na primeira ocorreu: a) análise documental de publicações, legislações e materiais que originaram a criação do Paic bem como promoveram suas transformações no decorrer de sua implementação; b) pesquisas no Scielo para identificação de artigos sobre a iniciativa. Na segunda, houve a pesquisa de campo com a realização de entrevistas semiestruturadas em profundidade com atores-chave da Seduc e ex-membros do governo cearense e de instituições parceiras, realizadas em 2016 (para a elaboração da tese de uma das autoras) e 2018 e 2019 com gestores da Seduc, professores e outros atores (no âmbito da Pesquisa Implementação de Políticas Educacionais e Equidade em Contextos de Vulnerabilidade Social, financiada pela Fapesp). A maioria das entrevistas foi presencial, ocorreu nos locais de trabalho dos participantes, com Termos de Consentimento Livre e Esclarecido (TCLC) assinados. Para complementar as análises, foram solicitados pedidos de informações, por meio da Lei de Acesso à Informação (LAI), no período de 2019 e 2020.

O presente artigo está estruturado em duas partes além da introdução. A primeira descreve os resultados educacionais alcançados no Estado do Ceará. A segunda trata das principais estratégias de gestão do Paic. Por fim, apresenta-se as considerações finais. 


\section{Equidade e outros resultados educacionais no Estado do Ceará}

O Ceará é um dos estados mais pobres do Brasil e tem uma população estimada de 9.132.078 habitantes (IBGE, 2019). Em 2010, 17,1\% da população do estado estava em situação de extrema pobreza (IPECE, 2015), uma taxa mais alta que a do Brasil (8,5\%). A desigualdade no estado é alta e o Índice de Gini era 0,560 em 2017.

Seu Índice de Desenvolvimento Humano (IDH) melhorou de 1991 a 2010, passando de 0,45 para 0,682, no período (PNUD; FUNDAÇÃO JOÃO PINHEIRO; IPEA, 2013). Na educação, foi de 0,204 para 0,615. Em 2017, o seu IDH-M foi de 0,735, assumindo a $15^{\text {a }}$ posição do Brasil (0,778), crescendo em todas as dimensões (IPEA, 2019).

Em 2017, a taxa de crianças alfabetizadas ao término do $2^{\circ}$ ano no Ceará $(89 \%)$ era maior do que a do Brasil e do Nordeste (IPECE, 2018), sendo que uma década atrás (2007) esse número era de apenas 39,9\% (CEARÁ, 2016b; 2019). O considerável aumento de estudantes no padrão desejável de desempenho nas redes municipal e estadual é acompanhado da redução do percentual de alunos não alfabetizados quando analisados os padrões de desempenho das redes públicas entre 2012 e 2015 (Figuras 1 e 2). Na avalição do final desse período, é revelada uma diminuição na desigualdade educacional no estado uma vez que todos os municípios cearenses se encontram nos padrões suficiente e desejável referente à alfabetização.

Figura 1 - Gráfico do percentual de estudantes por padrão de desempenho no $2^{\circ}$ ano do EF rede estadual (2012 a 2015)

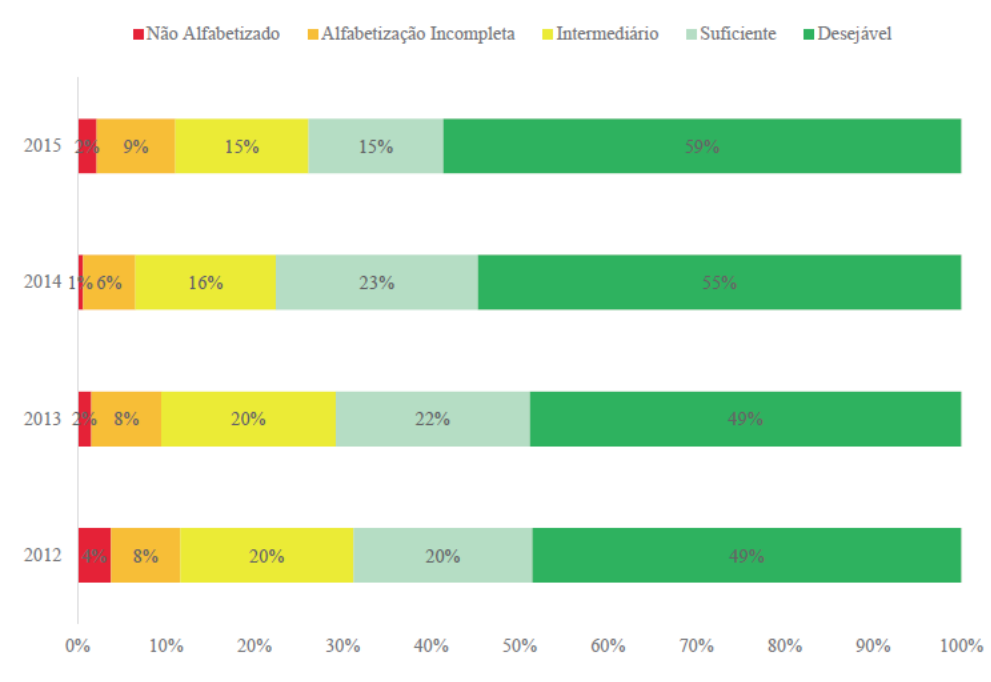

Fonte: Ceará (2016) 
Figura 2 - Gráfico do percentual de estudantes por padrão de desempenho no $2^{\circ}$ ano do EF rede municipal

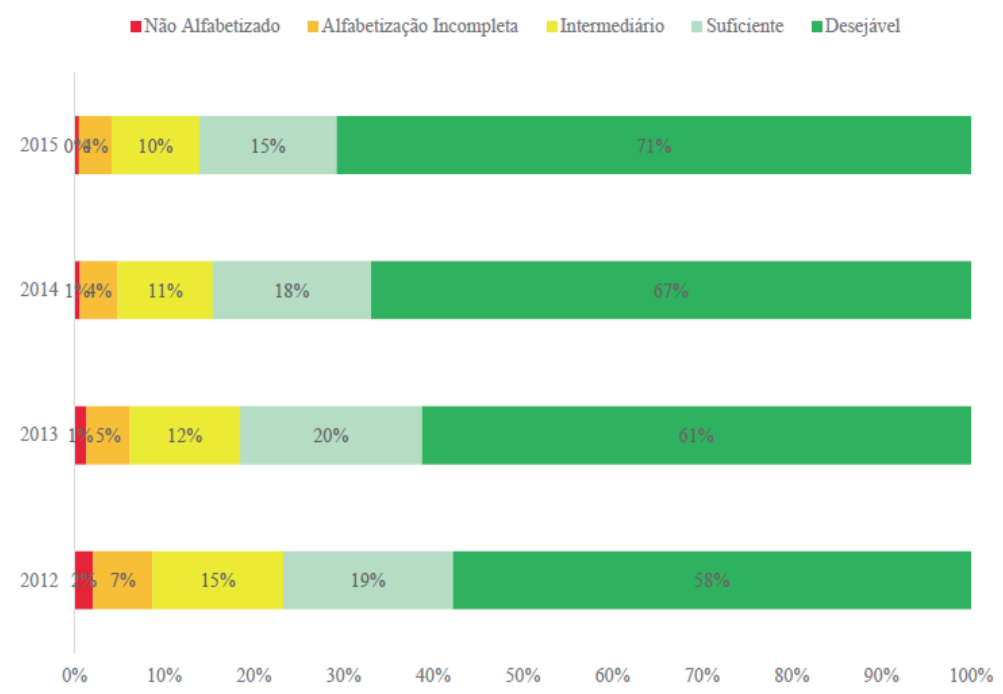

Fonte: Ceará (2016)

Os resultados da ANA para o ano de 2016 também apontam para a melhoria da alfabetização. A interpretação pedagógica dessa avaliação estabelece, que aqueles que estão no nível 3 (adequado) e 4 (desejável) na escala de proficiência apresentam aprendizagem suficiente no que concerne à leitura. Em 2016, 54,76\% dos alunos cearenses do $3^{\circ}$ ano estavam com aprendizagem suficiente na leitura, apontando para uma similaridade, ou até melhoria, em relação a São Paulo, 58,65\%; Espírito Santo, 52,64\%; Rio Grande do Sul, 51,06\%; e Rio de Janeiro, 40,25\%, que são estados com maior poder econômico do que o Ceará (INEP, 2017).

$\mathrm{Na}$ escrita, a ANA considera como suficiente a proficiência do aluno do $3^{\circ}$ ano que está nos níveis 4 (adequado) e 5 (desejável). No Ceará, são 70,71\% com escrita suficiente, percentual similar ou acima do resultado de São Paulo (82,9\%), do Espírito Santo (74,91\%), do Rio Grande do Sul (71,03\%) e do Rio de Janeiro (64,78\%). Na Matemática, no Ceará, $51,72 \%$ dos alunos têm proficiência suficiente; em São Paulo, são 60,82\%; no Espírito Santo, 53,59 \%; Rio Grande do Sul, 51,24\%; e Rio de Janeiro, 39,5\% (INEP, 2017).

O Índice de Desenvolvimento da Educação Básica (Ideb) nos anos iniciais do EF, no Brasil, em todas as regiões brasileiras, avançou nas redes públicas. Em 2017, o índice do país foi de 5,5 na avaliação do $5^{\circ}$ ano, superando a meta estabelecida para o ano em 0,3 ponto. $\mathrm{Na}$ região Nordeste, a meta também é superada em 0,6 ponto. O Ceará é o estado brasileiro que 
mais evolui no $5^{\circ}$ ano: o Ideb era de 2,8, em 2005, e passa para 6,1, em 2017 (Tabela 1), acima da média nacional e das metas projetadas para 2017 (4,5 pontos) e 2021 ( 5,1 pontos $){ }^{5}$

Tabela 1 - Ideb observado e metas projetadas da rede de ensino pública do Ceará, por séries do EF (2005 a 2017)

\begin{tabular}{|c|c|c|c|c|c|c|c|c|c|c|c|c|c|c|c|}
\hline \multirow{2}{*}{ Série/Ano } & \multicolumn{7}{|c|}{ Ideb Observado } & \multicolumn{8}{|c|}{ Metas Projetadas } \\
\hline & 2005 & 2007 & 2009 & 2011 & 2013 & 2015 & 2017 & 2007 & 2009 & 2011 & 2013 & 2015 & 2017 & 2019 & 2021 \\
\hline $\begin{array}{c}4^{\mathrm{a}} \text { série / } \\
5^{\mathrm{o}} \text { ano } \\
8^{\mathrm{a}} \text { série / }\end{array}$ & 2,8 & 3,5 & 4,1 & 4,7 & 5,0 & 5,7 & 6,1 & 2,9 & 3,2 & 3,6 & 3,9 & 4,2 & 4,5 & 4,8 & 5,1 \\
\hline $9^{\circ}$ ano & 2,8 & 3,3 & 3,6 & 3,9 & 4,1 & 4,5 & 4,9 & 2,8 & 3,0 & 3,3 & 3,6 & 4,0 & 4,3 & 4,6 & 4,8 \\
\hline
\end{tabular}

Fonte: Inep (2018)

Obs.: Os resultados marcados em verde referem-se ao Ideb que atingiu a meta.

Na avaliação do Ideb de 2017, dos anos iniciais do EF, 82 das 125 melhores escolas públicas brasileiras encontram-se no Ceará (IPECE, 2018).

A aprendizagem dos alunos do $5^{\circ}$ ano em LP e Matemática, também melhora, no Ceará, de 2008 a 2017. Em LP, em 2008, 6,8\% dos alunos da rede pública estavam no nível adequado, enquanto, em 2017, 50,3\%. Em Matemática, era 3,6\% e passa para 36,71\% (CEARÁ, 2016b; 2019).

Kasmirski, Gusmão e Ribeiro (2017) destacam que o Paic aumentou a proporção de alunos que atingem a proficiência apropriada em LP, em especial, em escolas cuja maioria dos alunos é pobre, ampliando, no estado, a equidade na educação. Entre 2005 e 2013, a média de proficiência do estado amplia 26\%; a nordestina, $16 \%$; e a brasileira, $13 \%$. A proficiência média cresceu, no Ceará, em todas as classes econômicas (aproximadamente $13 \%$ ) e o estado mais do que dobrou o percentual de alunos que atinge 200 pontos — valor adequado de conhecimento na escala do Saeb - com destaque para as crianças de menor nível socioeconômico. O programa teve efeito mínimo de 9 pontos percentuais (p.p.) para escolas não pobres e impacto adicional para escolas pobres que varia entre 2 e 6 p.p. (KASMIRSKI; GUSMÃO; RIBEIRO, 2017, p. 22).

Tanto no nível do aluno quanto no da escola, em relação a ambos os grupos de controle, o Paic aumentou a probabilidade de uma criança atingir o nível adequado de proficiência em LP. Os coeficientes variam de 9,6 a 13 pontos percentuais (p.p.). Considerando-se que o percentual de alunos com desempenho acima ou igual ao piso aumentou 25 p.p. entre 2007 e 2011 para a coorte (Tabela 2), pode-se dizer que o Paic foi responsável por, pelo

${ }^{5}$ Segundo QEdu (2018), em 2007, 98\% das escolas cearenses estavam em situação de atenção ou alerta no Ideb e, em 2017, 42\% estão nesta situação. No estado há 69 municípios que não possuem escolas em alerta.

RPGE- Revista on line de Política e Gestão Educacional, Araraquara, v. 24, n. 3, p. 1286-1311, set./dez. 2020. e-ISSN:1519-9029. 
menos, 39\% dessa elevação (KASMIRSKI; GUSMÃO; RIBEIRO, 2017, p. 22).

Nos anos finais do EF, as crianças passam a ser acompanhadas pelo Sistema Permanente de Avaliação da Educação Básica do Ceará (Spaece), a partir de 2012. Nesse ano, $8,6 \%$ dos alunos estavam no nível adequado em LP e, em 2017, amplia para 18,7\%. Já em Matemática, passou de 3,9\%, em 2012, para 9,6\%, em 2017 o percentual no nível adequado. $\mathrm{O}$ foco nos anos iniciais do ensino fundamental transbordou, de algum modo, gerando efeitos também nos anos finais.

Em 2008, nenhum município apresentava padrões adequados em Matemática e Português na $4^{\mathrm{a}}$ série $/ 5^{\circ}$ ano e na $8^{\mathrm{a}}$ série $/ 9^{\circ}$ (Quadro 2). Em 2017, são 84 em níveis adequados em Português e 40 em Matemática no $5^{\circ}$ ano, e dois adequados em Português e um em Matemática, no $9^{\circ}$ ano, e nenhum no nível muito crítico.

Quadro 2 - Quantidade de municípios cearenses, por padrões de proficiência em Matemática e Português (2008 e 2017)

\begin{tabular}{|c|c|c|c|c|}
\hline \multirow[t]{2}{*}{ Série/Ano } & \multicolumn{2}{|l|}{2008} & \multicolumn{2}{|l|}{2017} \\
\hline & Português & Matemática & Português & Matemática \\
\hline \multirow{4}{*}{$4^{\mathrm{a}}$ série $/ 5^{\circ}$ ano } & $\begin{array}{l}0 \text { municípios muito } \\
\text { críticos }\end{array}$ & $\begin{array}{l}2 \text { municípios muito } \\
\text { críticos }\end{array}$ & $\begin{array}{l}0 \text { municípios muito } \\
\text { críticos }\end{array}$ & $\begin{array}{l}0 \text { municípios } \\
\text { muito críticos }\end{array}$ \\
\hline & 166 críticos & 180 críticos & 0 críticos & 6 críticos \\
\hline & 18 intermediários & 2 intermediários & 100 intermediários & $\begin{array}{l}129 \\
\text { intermediários }\end{array}$ \\
\hline & 0 adequados & 0 adequados & 84 adequados & 49 adequados \\
\hline \multirow[t]{4}{*}{$8^{a}$ série $/ 9^{\circ}$ ano } & $\begin{array}{l}17 \text { municípios muito } \\
\text { críticos }\end{array}$ & $\begin{array}{l}125 \text { municípios muito } \\
\text { críticos }\end{array}$ & $\begin{array}{l}0 \text { municípios muito } \\
\text { críticos }\end{array}$ & $\begin{array}{l}0 \text { municípios } \\
\text { muito críticos }\end{array}$ \\
\hline & 166 críticos & 57 críticos & 52 críticos & 151 críticos \\
\hline & 0 intermediários & 1 intermediários & 130 intermediários & 32 intermediários \\
\hline & 0 adequados & 0 adequados & 2 adequados & 1 adequado \\
\hline
\end{tabular}

Fonte: Ceará (2018)

Observa-se também melhoria da taxa de distorção idade-série na rede pública do Ceará. Essa taxa era de 26\% em 2006 e, em 2018, é de 9\%, enquanto no Brasil era de 25\% e 13\%, respectivamente (QEDU, 2018, 2006), conforme se pode depreender da Figura 3. 
Figura 3 - Gráfico da evolução da taxa de distorção idade-série do Ceará e do Brasil (2006 e 2018)
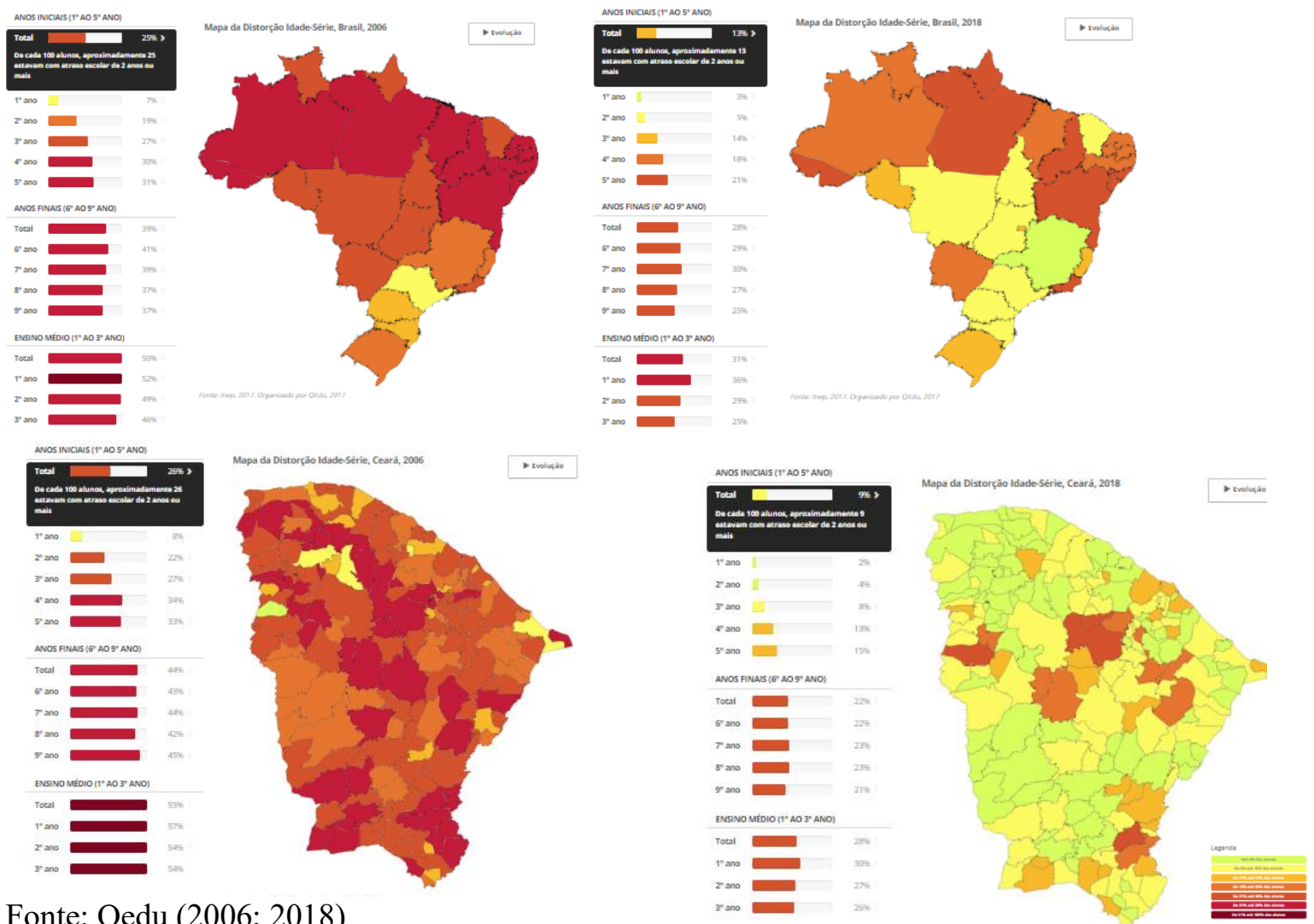

Fonte: Qedu (2006; 2018)

A taxa de analfabetismo, em 2017, é elevada (14,2\%), mas está decrescendo mais acentuadamente do que em outros estados do Nordeste e no Brasil, em especial na faixa entre 7 e 14 anos, pós-2008 (IPECE, 2018; COSTA; CARNOY, 2015). O analfabetismo passa a se concentrar nas gerações mais velhas, que não tiveram acesso à educação na idade correta.

Costa e Carnoy (2015) buscaram identificar se os declínios mais rápidos na taxa de analfabetismo, após 2007, e os desempenhos melhores em Leitura e Matemática no EF, em comparação com outros estados, estavam diretamente vinculados ao Paic ou se tinham efeitos de outras ações educacionais aplicadas de 2007 a 2011. Os autores mostram que o programa tem impacto no desempenho do aluno em Português e Matemática. O estudo de Kasmirski, Gusmão e Ribeiro (2017) também mostra a relevância do Paic na melhoria do desempenho dos alunos em LP, indicando que o programa foi responsável por, pelo menos, 39\% dessa elevação dos resultados.

No Ceará, as taxas de rendimento, importantes para o conceito de equidade, no EF também são melhores do que no Brasil em 2017. A reprovação é de 3,0\% nos anos iniciais e $6,1 \%$ nos anos finais; o abandono é de $0,5 \%$ e $2,2 \%$, respectivamente, e a aprovação, de 96,5\% e 91,6\% (QEDU, 2018). Ainda como resultados que afetam a equidade estão: 
ampliação do perfil técnico dos Dirigentes Municipais de Educação e sua importância para as gestões municipais; ampliação do nível de escolaridade dos professores; fortalecimento da autoestima docente e sua valorização; importância dada à primeira infância, entre outros (SEGATTO, 2015; CRUZ, 2017).

Codes et al. (2019, p. 8) mostram outros resultados de equidade na aprendizagem do Ceará que contradizem a tendência de que o: "aprendizado das crianças seja menor em locais com altas taxas de analfabetismo". De acordo com esses autores, a:

taxa de analfabetismo está muito acima da nacional, mas suas crianças estão aprendendo, na média, mais que a média das crianças brasileiras. Os outros oito estados nordestinos - envolvidos pelo retângulo - seguem o padrão geral, com altas taxas de analfabetismo associadas a baixos valores do Ideb (CODES et al., 2018, p. 8).

Apesar dos esforços de universalização do acesso e avanços na equidade, a taxa líquida de matrícula no EF — 6 a 14 anos — em 2018 era de 98,7\% (ANUÁRIO BRASILEIRO DA EDUCAÇÃO BÁSICA, 2019), indicando que há crianças fora da escola e novas estratégias precisam ser adotas em especial com relação às crianças dos anos finais do EF.

\section{A organização da Seduc para a implementação do Paic e suas estratégias de gestão}

A eleição do governador Cid Gomes, em 2007, foi uma janela de oportunidade para o Paic entrar na agenda governamental, criando instrumentos de colaboração entre o estado e os municípios (KINGDON, 1995). Os resultados da experiência de Sobral (INEP, 2005), o pacto firmado na Assembleia Legislativa com o Comitê Cearense para a Eliminação do Analfabetismo Escolar e o processo de comunicação com a sociedade foram essenciais para sua formulação e implementação (CEARÁ, 2012).

A ex-Secretária de Educação (gestão 2007-2014) afirmou, em entrevista que:

[...] nós tínhamos a experiência de Sobral, no enfrentamento ao analfabetismo escolar, como realidade que nós constatamos, no caso de Sobral, em 2001, e também já tinha acontecido o comitê na Assembleia Legislativa, que tinha sido implantado quando o Ivo foi para a Assembleia Legislativa como deputado estadual. Ele fez uma proposição à mesa diretora da Assembleia de instalar o Comitê Cearense pela Eliminação do Analfabetismo Escolar, quer dizer, esse Comitê, eu considero que foi uma semente muito importante do Paic. [...] Foi um processo de chamamento, convite aos municípios para uma adesão, no primeiro momento fizemos alguns combinados em relação a avaliação que seria feita, o desafio mesmo

RPGE- Revista on line de Política e Gestão Educacional, Araraquara, v. 24, n. 3, p. 1286-1311, set./dez. 2020. e-ISSN:1519-9029. DOI: https://doi.org/10.22633/rpge.v24i3.13904 
que nos movia, que era garantir o sucesso da alfabetização dos alunos, das crianças na idade certa.

As entrevistas e referências mostram que houve uma pactuação, entre os diversos atores, sobre a importância do estado fornecer uma educação de qualidade para todos e que esta era a base para a geração de riquezas no estado e uma alternativa para a redução da pobreza e da desigualdade, resultando numa convergência de esforços para adesão de todos os municípios cearenses ao Paic. O Programa foi adotado por todos os 184 municípios e tem sido visto como um fator chave para o Ceará obter bons resultados nos processos de avaliação estadual e nacional do EF.

A Seduc, para desempenhar suas funções, contava, em março de 2019, com 59.537 servidores, dos quais 48.923 eram efetivos e 10.614 contratados por tempo determinado (CEARÁ, 2019a). De 2008 a 2010, houve um investimento de R\$ 104.331.586,38 no Paic (CEARÁ, 2012). De 2012 a 2018, foram pagos R\$ 92.313.179,73 (CEARÁ, 2019a). O Ceará possui uma baixa capacidade de financiamento e é dependente da complementação da União com relação ao Fundo de Manutenção e Desenvolvimento da Educação Básica e de Valorização dos Profissionais da Educação (Fundeb). Em 2017, "seu valor aluno/ano foi o sexto menor - R $\$ 2.184,94$ - entre os vinte e sete federados, demandando um repasse de $\mathrm{R} \$$ 1,33 bilhão para atingir o piso nacional - R\$ 2.875,03" (CODES et al., 2018, p. 8), situação que justifica a importância de estudos sobre as estratégias de gestão do Paic, considerando os resultados apresentados acima

A partir da cooperação entre estado e municípios, foram estabelecidas as atribuições de cada ator (Seduc e seus órgãos, prefeituras e Secretarias Municipais de Educação (SMEs), universidades, direção da escola, professores, alunos e família); definidos procedimentos padronizados; ofertadas formações continuadas com o foco na aprendizagem; disponibilizados materiais; estabelecidos mecanismos de indução à implementação da política; e fortalecido o sistema de acompanhamento e avaliação. A política prevê as mesmas estratégias para todos os municípios o que uniformiza diretrizes e ao mesmo tempo busca adaptá-las à realidade de cada município, bem como um processo permanente de avaliação.

O Paic cria padrões técnicos e instrumentais, produz materiais orientadores e oferece formações aos professores para que organizem as aulas de modo a promover o aprendizado esperado, rompendo com as desigualdades entre os municípios e entre escolas. Há, ainda, estratégias de reforço escolar para a regularização do fluxo escolar. $\mathrm{O}$ apoio técnico do estado reduz o esforço necessário para que cada município crie o seu modelo de aprendizagem. $\mathrm{O}$ programa também vem conseguindo difundir uma crença coletiva de que é possível 
alfabetizar todas as crianças, independentemente da sua origem. Coexistem um movimento de descentralização da gestão para os municípios e um de centralização da política educacional com a indução do estado por meio de condicionalidades pactuadas, denominado por Padilha e Batista (2013) “descentralização orquestrada".

Na sua concepção original, o Paic foi estruturado com cinco eixos (gestão da educação municipal, alfabetização, formação do leitor, avaliação externa e Educação Infantil), priorizando a alfabetização e gestão. Com os resultados alcançados, isso foi ampliado de de forma incremental até o $9^{\circ}$ ano e incluindo outras disciplinas.

Em 2020, o Programa apresenta seis eixos de atuação: a) gestão municipal; b) EF I; c) EF II e educação integral ${ }^{6}$; d) Educação Infantil; e) literatura infantil e formação de leitores; e f) avaliação externa (Quadro 1). Cada eixo possui objetivos e metas que foram pactuados entre os atores estaduais e municipais, e qualquer alteração é acordada entre os envolvidos. Em cada um há objetivos, metas estabelecidas, atores envolvidos e ações preconizadas que são acompanhados pelas equipes municipais, regionais e central da secretaria.

\section{Quadro 1 - Eixos do Paic}

\begin{tabular}{|c|c|c|c|c|}
\hline Eixo & Objetivo & Metas & Atores Envolvidos & Ações \\
\hline 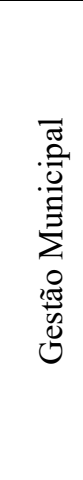 & $\begin{array}{l}\text { - Fortalecer } \\
\text { institucionalmente os } \\
\text { "sistemas municipais } \\
\text { de ensino, envolvendo } \\
\text { assessoria técnica para } \\
\text { a estruturação de } \\
\text { modelo de gestão } \\
\text { focado no resultado da } \\
\text { aprendizagem" } \\
\text { (CEARÁ, 2016c). }\end{array}$ & $\begin{array}{l}\text { Criar e disseminar } \\
\text { uma cultura de gestão } \\
\text { do sistema municipal } \\
\text { e de gestão escolar } \\
\text { voltada para a } \\
\text { aprendizagem dos } \\
\text { alunos, com a } \\
\text { valorização do } \\
\text { magistério e } \\
\text { processos formativos } \\
\text { permanentes }\end{array}$ & Seduc e municípios & $\begin{array}{l}\text { Ações para a melhoria } \\
\text { da capacidade } \\
\text { institucional das SME e } \\
\text { das escolas, criando } \\
\text { uma cultura de } \\
\text { planejamento e } \\
\text { acompanhamento das } \\
\text { ações, inclusive } \\
\text { apoiando a busca ativa } \\
\text { dos alunos e o processo } \\
\text { de aprendizagem de } \\
\text { cada aluno }\end{array}$ \\
\hline
\end{tabular}

${ }^{6}$ Eixo inserido em 2015.

RPGE- Revista on line de Política e Gestão Educacional, Araraquara, v. 24, n. 3, p. 1286-1311, set./dez. 2020. e-ISSN:1519-9029. DOI: https://doi.org/10.22633/rpge.v24i3.13904 


\begin{tabular}{|c|c|c|c|c|}
\hline $\overrightarrow{\mid c}$ & $\begin{array}{l}\text { - Implementar } \\
\text { propostas didáticas de } \\
\text { alfabetização; } \\
\text { - Produzir materiais } \\
\text { didáticos estruturados } \\
\text { para professores e } \\
\text { alunos do } 1^{\circ} \text { e } 2^{\circ} \text { anos } \\
\text { e material de apoio } \\
\text { pedagógico } \\
\text { - Realizar a formação } \\
\text { docente continuada e } \\
\text { em serviço, nos } \\
\text { municípios, por } \\
\text { formadores do Mais } \\
\text { Paic; entre outras } \\
\text { práticas. }\end{array}$ & $\begin{array}{l}\text { Alfabetização de } \\
100 \% \text { das crianças, } \\
\text { até o final do } 2^{\circ} \text { ano } \\
\text { do EF, e a } \\
\text { alfabetização dos } \\
\text { alunos não } \\
\text { alfabetizados do } 3^{\circ} \text { ao } \\
5^{\circ} \text { ano do EF } \\
\text { (CEARÁ, 2016d), } \\
\text { bem como a formação } \\
\text { continuada presencial } \\
\text { para professores das } \\
\text { redes municipal e } \\
\text { estadual e o } \\
\text { fortalecimento do } \\
\text { processo de } \\
\text { acompanhamento } \\
\text { pedagógico com o } \\
\text { fornecimento de } \\
\text { materiais pedagógicos }\end{array}$ & $\begin{array}{l}\text { Professores e } \\
\text { alunos do } 3^{\circ} \text { ao } 5^{\circ} \\
\text { ano do EF }\end{array}$ & $\begin{array}{l}\text { - Cooperação técnico- } \\
\text { pedagógica aos } \\
\text { municípios; } \\
\text { - Rotinas, atividades, } \\
\text { suporte teórico }\end{array}$ \\
\hline 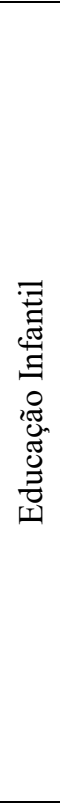 & $\begin{array}{l}\text { - "Contribuir para a } \\
\text { promoção da } \\
\text { qualidade do } \\
\text { atendimento oferecido } \\
\text { às crianças e suas } \\
\text { famílias nas } \\
\text { instituições"; } \\
\text { - "colaborar no } \\
\text { processo de } \\
\text { implantação e } \\
\text { implementação das } \\
\text { propostas pedagógicas } \\
\text { e programas de } \\
\text { formação continuada } \\
\text { de professores da } \\
\text { educação infantil dos } \\
\text { municípios } \\
\text { participantes do } \\
\text { programa" (CEARÁ, } \\
\text { 2016e). }\end{array}$ & $\begin{array}{l}\text { Ampliar o } \\
\text { atendimento das } \\
\text { crianças de até } 3 \text { anos } \\
\text { e universalizar o } \\
\text { atendimento das } \\
\text { crianças de } 4 \text { e } 5 \text { anos } \\
\text { de idade }\end{array}$ & $\begin{array}{l}\text { Parceria do Fórum } \\
\text { Estadual de } \\
\text { Educação Infantil } \\
\text { do Ceará (Feic) e } \\
\text { de universidades }\end{array}$ & $\begin{array}{l}\text { - Orientações } \\
\text { curriculares para a } \\
\text { Educação Infantil } \\
\text { trabalhadas nas } \\
\text { formações } \\
\text { - Financiamento de } \\
\text { unidades de Educação } \\
\text { Infantil } \\
\text { - Os municípios } \\
\text { cearenses atendem da } \\
\text { Educação Infantil aos } \\
\text { anos finais do EF (5 ao } \\
9^{\circ} \text { ano), e o estado os } \\
\text { apoia, com assistência } \\
\text { técnica à aprendizagem } \\
\text { na idade certa, por meio } \\
\text { do Programa. }\end{array}$ \\
\hline 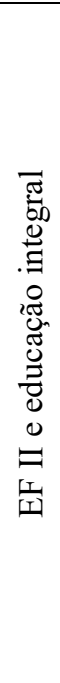 & $\begin{array}{l}\text { - Fortalecer a } \\
\text { aprendizagem dos } \\
\text { estudantes }\end{array}$ & $\begin{array}{l}\text { Ideb na rede pública } \\
\text { de } 5,0 \text { em } 2018 ; \text { ter } \\
\text { pelo menos } 25 \% \text { dos } \\
\text { estudantes no nível } \\
\text { adequado e, no } \\
\text { máximo, } 44 \% \text { nos } \\
\text { níveis crítico e muito } \\
\text { crítico em LP, e pelo } \\
\text { menos } 16 \% \text { dos } \\
\text { estudantes no nível } \\
\text { adequado e, no } \\
\text { máximo, } 70 \% \text { no } \\
\text { nível adequado em } \\
\text { Matemática; reduzir o } \\
\text { abandono a } 2,5 \% \text {, } \\
\text { entre outras (CEARÁ, } \\
\text { 2016f). }\end{array}$ & $\begin{array}{l}\text { Estudantes e } \\
\text { professores }\end{array}$ & $\begin{array}{l}\text { Formação de } \\
\text { professores com } \\
\text { orientações de } \\
\text { acompanhamento, } \\
\text { mecanismos de } \\
\text { reconhecimento e } \\
\text { incentivos específicos }\end{array}$ \\
\hline
\end{tabular}

RPGE- Revista on line de Política e Gestão Educacional, Araraquara, v. 24, n. 3, p. 1286-1311, set./dez. 2020. e-ISSN:1519-9029. 


\begin{tabular}{|c|c|c|c|c|}
\hline 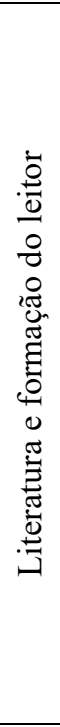 & $\begin{array}{l}\text { - Garantir o "direito da } \\
\text { criança ao } \\
\text { desenvolvimento } \\
\text { humano, à formação } \\
\text { cultural e à inclusão } \\
\text { social, com o acesso à } \\
\text { literatura infantil, } \\
\text { promovendo a } \\
\text { aquisição, a } \\
\text { distribuição e a } \\
\text { dinamização de } \\
\text { acervos" (CEARÁ, } \\
\text { 2016g). }\end{array}$ & $\begin{array}{l}100 \% \text { das crianças } \\
\text { dos municípios com } \\
\text { acesso a acervo } \\
\text { literário e lido um } \\
\text { mínimo de cinco } \\
\text { livros por ano; } \\
\text { realização de oficinas } \\
\text { de dinamização da } \\
\text { leitura aos professores } \\
\text { da Educação Infantil e } \\
\text { séries iniciais do EF, } \\
\text { com pelo menos } 40 \\
\text { horas por ano, desde } \\
\text { 2008 formação de } \\
\text { acervo literário nas } \\
\text { salas de aula, com, no } \\
\text { mínimo, cinco livros } \\
\text { por aluno, entre outras }\end{array}$ & $\begin{array}{l}\text { Alunos e } \\
\text { Professores; Seduc }\end{array}$ & $\begin{array}{l}\text { - Formação dos } \\
\text { professores orientando- } \\
\text { os a dinamizar o acervo } \\
\text { e incentivar os alunos e } \\
\text { os próprios docentes a } \\
\text { lerem. } \\
\text { - Aquisição e } \\
\text { distribuição de livros de } \\
\text { editoras aos municípios } \\
\text { - Organização da } \\
\text { revista Pense! com } \\
\text { resenhas literárias, } \\
\text { relatos de experiências, } \\
\text { artigos e ensaios } \\
\text { voltados para a } \\
\text { formação de leitores }\end{array}$ \\
\hline 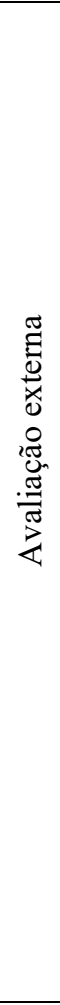 & $\begin{array}{l}\text { - Difundir uma cultura } \\
\text { de avaliação do } \\
\text { processo de } \\
\text { aprendizagem dos } \\
\text { alunos, de forma } \\
\text { apropriada, } \\
\text { responsável e ética, } \\
\text { almejando melhorias } \\
\text { contínuas no processo } \\
\text { de ensino e } \\
\text { aprendizagem; } \\
\text { - Diagnosticar a } \\
\text { situação da } \\
\text { aprendizagem e } \\
\text { comunicar os } \\
\text { resultados de avaliação } \\
\text { por município, escola, } \\
\text { turma e aluno; e } \\
\text { - Fornecer subsídios } \\
\text { para que a Seduc } \\
\text { desenvolva uma gestão } \\
\text { focada na } \\
\text { aprendizagem, entre } \\
\text { outros. (CEARÁ, } \\
\text { 2016h). }\end{array}$ & $\begin{array}{l}\text { Avaliações } \\
\text { diagnósticas anuais, } \\
\text { com as crianças } \\
\text { matriculadas nas } \\
\text { séries iniciais do EF } \\
\left(2^{\circ} \text { ao } 5^{\circ} \text { ano }\right) \text { em } \\
\text { todos os municípios; } \\
\text { disponibilização de } \\
\text { sistema informatizado } \\
\text { para digitação dos } \\
\text { dados das avaliações } \\
\text { externas; divulgação } \\
\text { dos resultados entre } \\
\text { diretores, supervisores } \\
\text { e professores, } \\
\text { objetivando melhorar } \\
\text { a qualidade da } \\
\text { educação nas séries } \\
\text { iniciais do EF, entre } \\
\text { outras práticas. }\end{array}$ & $\begin{array}{l}\text { Seduc, Credes, } \\
\text { secretarias } \\
\text { municipais }\end{array}$ & $\begin{array}{l}\text { - Avaliações no final do } \\
\text { ano letivo; } \\
\text { - Divulgação ampla de } \\
\text { seus resultados; } \\
\text { - Criação de "cadeia de } \\
\text { vigilância" } \\
\text { (KASMIRSKI, } \\
\text { GUSMÃO; RIBEIRO, } \\
\text { 2017, p. 11) }\end{array}$ \\
\hline
\end{tabular}

Fonte: Elaboração própria

Destaca-se que o foco do eixo avaliação é conhecer os aprendizados e as dificuldades de cada educando e propor ações de correção de rumo e de apoio aqueles municípios, escolas e professores que não estejam atingindo os resultados esperados. A relevância da avaliação como meio de acompanhamento dos resultados é confirmada em entrevistas feitas com professores em Fortaleza:

A gente vê as questões que os alunos mais erraram e acertaram para ter uma ideia do que eles já dominam e do que eles ainda precisam dominar. Além disso a gente também vê os alunos que, de modo geral, tiraram boas 
notas e alunos que não tiraram boa nota. Então a gente tem uma ideia do aluno que está com mais dificuldade... (professora do $5^{\circ}$ ano, escola 2).

As medidas originadas na Seduc são apoiadas pelas 20 Coordenadorias Regionais de Desenvolvimento da Educação (Credes) e secretarias municipais e devem chegar às escolas e salas de aula de todos os municípios, criando o que Kasmirski, Gusmão e Ribeiro (2017, p. 11) denominam "cadeia de vigilância". No programa há avaliações diagnósticas com as perspectivas formativa e somativa o que possibilita a definição de estratégias para promover a aprendizagem direcionada a cada aluno, sala e escola. Também são realizadas avaliações externas apara avaliar se os alunos estão adquirindo as competências e habilidades esperadas com os avanços obtidos e os problemas a serem enfrentados (SPAECE, 2018).

Segundo Gusmão e Ribeiro (2011), os processos avaliativos são instrumento de intervenção pedagógica e todos os envolvidos - Seduc, Credes, SMEs, diretores, professores e familiares e a sociedade - tomam conhecimento dos resultados. O desempenho também orienta as formações. As equipes do Programa têm sido formadas para desenvolver ações focadas e assistência técnica àqueles municípios e escolas com piores desempenhos (CRUZ, 2017).

O Paic contou com a reestruturação interna da Seduc que assumiu o compromisso de assessorar tecnicamente os municípios nos eixos do programa, buscando respeitar os contextos locais, desenvolvendo formações e avaliando os resultados por meio de um sistema próprio de avaliação. Os municípios, em contrapartida, forneciam o apoio logístico e os materiais necessários para as atividades do Paic (CEARÁ, 2012) e disponibilizavam as equipes locais para implementação das propostas.

Dentre esses mecanismos para implementação, cria-se a Coordenadoria de Cooperação com os Municípios (Copem) como braço executivo da Seduc. A Copem reestrutura as 20 Credes que, com os núcleos Regionais de Cooperação com Municípios (NRCOM), que auxiliam três frentes garantidoras das ações na ponta da política, são elas: comunicação, implementação e acompanhamento da política educacional local. Outro aspecto que contribui para o arranjo de implementação da Copem é sua estratégia de atuação organizada segundo os eixos do programa.

A atuação na formação e acompanhamento deste processo ocorre em dois níveis: atuação na ponta com os professores multiplicadores nas Credes e, acompanhamento gerencial por meio da Seduc. Cada município participante conta com um gerente local do Mais Paic, com função de acompanhar e responsabilidade de ser interlocutor entre a Seduc e os municípios e, com um professor multiplicador para cada segmento educacional. A atuação 
com os professores multiplicadores é pautada na formação contínua baseado no trabalho político-pedagógico de cada segmento educacional. Tais formações ocorrem periodicamente, e esses profissionais reproduzem as atividades formativas para a rede a qual pertence e, as práticas bem-sucedidas dos municípios são disseminadas neste ambiente (VIEIRA; VIDAL, 2013). A agente implementadora de nível macro, orientadora da célula de gestão do Paic na Copem, afirma que a Crede faz uso de visitas como meio de verificação das necessidades locais:

[...] quando estava na Crede, fazia visitas [aos municípios] e eu via a realidade, o que estavam precisando. [...] Depois da formação [que reúne os formadores das Credes], a equipe aqui da Copem vai fazer a visita em cada Crede [...] E eles acompanham as formações que estão acontecendo lá para saber se elas estão sendo repassadas de acordo com o que foi planejado.

Para que os conteúdos das capacitações sejam aplicados na atuação direta com os alunos, a implementação conta com uma equipe municipal de quatro a seis pessoas e o suporte do governo estadual subsidiando bolsas de extensão tecnológica para o gerente local e os professores multiplicadores, tendo em consideração a realidade local de cada municípios e, bolsas de atendimento à equipe especializada, que tem como foco de sua atuação, implementar os objetivos estratégicos do programa.

Em Fortaleza, professoras afirmam que a formação organizada no âmbito do Paic tem relação com o que é dado em sala de aula:

A formação é organizada pelo distrito [em Fortaleza]. Parte da SME e depois, o distrito. A formação ocorre todo mês. Costumo ir. (professora do $4^{\mathrm{o}}$ ano, escola Fortaleza).

Temos formação no distrito, uma vez por mês. Falam dos conteúdos. Bate com os conteúdos que estão sendo dados na sala de aula. Porque tem acompanhamento pelos conteúdos dos livros didáticos. [A questão da formação é] como você trabalharia tal conteúdo na sala de aula para que o aluno tenha um aprendizado satisfatório? (professora do $5^{\circ}$ ano, escola Fortaleza).

Além deste arranjo dos atores estaduais e municipais, há também a articulação com o Ministério da Educação. Também integra este processo de implementação, parceria estratégicas com a UFC, o Unicef, a Associação para o Desenvolvimento dos Municípios do Estado do Ceará (APDM/CE), o Feic, a Aprece, a União Nacional dos Conselhos Municipais de Educação (Uncme), a Undime e a Fundação Cearense de Apoio ao Desenvolvimento Científico e Tecnológico (Funcap), editoras de materiais didáticos e consultorias de apoio. 
Esse arranjo de apoio técnico e financeiro com diversas instituições governamentais e não governamentais foi sendo construído, desde a década de 1970, a partir do alcance de resultados, aprendizado contínuo, laços de confiança, inovações e pelo "papel de lideranças políticas e técnicas capazes de estruturar e defender determinados projetos, fazendo a ponte entre o modelo técnico e a dinâmica política” (ABRUCIO; SEGATTO; PEREIRA, 2016, p. 29).

A partir da experiência de Sobral foram estruturados dois mecanismos de indução financeira: a) destinação de parcela da cota-parte dos municípios do Imposto sobre Operações relativas à Circulação de Mercadorias e Prestação de Serviços de Transporte Interestadual e Intermunicipal e de Comunicação (ICMS), às prefeituras, em função dos seus resultados de aprendizagem (CEARÁ, 2012); e b) prêmio Escola Nota Dez às melhores escolas (CRUZ, 2019). Esses instrumentos indutores proporcionam que a educação entre na agenda municipal e seja priorizado o processo de aprendizagem nas escolas e se inicie uma cultura de acompanhamento de resultados e uso de indicadores.

Os critérios de distribuição da cota-parte dos municípios no ICMS (25\% do total) foram alterados pela Lei 14.023/2007 e os repasses baseiam-se no desempenho de educação (18\%), saúde (5\%) e meio ambiente (2\%). Os $18 \%$ da cota-parte dos municípios é distribuído em função do Índice Municipal de Qualidade Educacional de cada localidade, formado pela taxa de aprovação dos alunos do $1^{\circ}$ ao $5^{\circ}$ ano do EF e pela média obtida pelos alunos de $2^{\circ}$ e $5^{\circ}$ anos da rede municipal em avaliações de aprendizagem do Spaece. Desta forma os prefeitos passam a acompanhar os seus resultados educacionais. Segundo Segatto (2015, p. 109) a distribuição do ICMS, apesar de priorizar a educação, "não considera o nível socioeconômico dos alunos, ou seja, não visa reduzir desigualdades educacionais entre os municípios". Todavia, segundo a autora, essa modificação na cota-parte beneficiou a maior parte dos municípios. Segundo um agente implementador de nível macro/Seduc, coordenador do Prêmio Nota dez:

[...] o que acontece? Nestes 25\% é que ele transformou em 18 para a educação, 5 para a saúde, 2 para o meio-ambiente. Antes do Governo Cid Gomes, estes $25 \%$ eram distribuidos praticamente [de forma igualitária]. E só ia para os grandes municipios. Hoje, com esses $18 \%$ aqui, tem municipio desse aqui que dobrou o seu ICMS com o resultado na educação. É o principal meio de recurso - é o resultado da educação. E aí, para o prefeito que entende isso aí, e de vez em quando eles são chamados para mostrar esses dados aí... E ele, se ele realmente tiver interesse em dobrar o ICMS dele, ele vai cair em cima do Secretário de Educação e vai dizer: "olha, vamos, vamos"... É assim que se faz, é assim que se alcança. Porque tem toda uma política por trás disso, certo? 
O prêmio Escola Nota Dez é concedido anualmente às escolas que apresentam os melhores desempenhos no processo de aprendizagem e envolve as equipes escolares com o processo de aprendizagem. Criado pela Lei 14.371/2009, estava inicialmente vinculado à melhoria dos resultados da alfabetização e socialização das práticas educativas. O repasse, realizado em duas parcelas, exigia que a escola premiada apoiasse com outra unidade escolar, com desempenho ruim, por um ano. Este arranjo de cooperação entre unidades escolares é uma forma de socializar conhecimentos, promover a colaboração e buscar a equidade em toda a rede (VIEIRA; VIDAL, 2013; CALDERÓN; RAQUEL; CABRAL, 2015).

A premiação é divulgada na mídia e muito valorizada pelos prefeitos e equipes escolares, pois além do recurso recebido há o reconhecimento público da sua qualidade (SEGATTO, 2015; ARAÚJO; LEITE; ANDRIOLA, 2019). Reformulações foram realizadas para o aprimoramento do prêmio pelas leis 15.052/2011, 15.523/2015 e 15.923/2015, e em 2020, premia as 150 unidades escolares com os melhores resultados nos $2^{\circ}, 5^{\circ}$ e $9^{\circ}$ anos, mas o resultado da escola está vinculado ao do município e de outras escolas da Crede, indicando uma "diretriz de melhoria da educação para toda a rede, todas as regiões e todos os alunos" (CRUZ, 2019, p. 17).

O Prêmio tem um capital politico muito forte: prefeito vinha trazer as suas escolas... A escola é premiada, pega um prêmio, um troféu, uma placa, leva para dentro do município e diz "Olha aí, nós conseguimos os resultados!", recebe da mão do governador e é feita uma festa imensa com milhares de pessoas... Nós já chegamos a colocar até 10.000 pessoas num Centro de Eventos para essa premiação. Então, tem um capital político muito grande. (coord. Prêmio Nota Dez, na Copem).

A equipe da Seduc é composta por profissionais que já atuaram em municípios e, segundo os entrevistados, são sensíveis às demandas municipais, favorecendo a escuta e o diálogo permanente, o que proporciona o aprimoramento contínuo das ações. Os três dirigentes da Secretaria do Estado entrevistados eram professores universitários que atuaram na experiência de Sobral/CE. Os técnicos que concederam entrevistas são profissionais das redes de ensino que passaram a atuar na implementação do Paic, depois de terem se destacado em atuações (como professores, coordenadores pedagógicos, superintendentes, secretários de educação, técnicos de Credes e de secretarias municipais).

A equipe também apoia a implementação da política educacional por meio de programas estaduais (Centros de Educação Infantil, apoio ao transporte escolar) e divulgando e assessorando os municípios para acessar às iniciativas federais. 
A Seduc coordena a política de educação e coopera com os municípios por meio de parcerias técnicas e financeiras (SEGATTO, 2015; CRUZ, 2019). As assistências técnica e financeira vem ampliando, de forma contínua, buscando a manutenção de um pacto entre os atores governamentais e não governamentais de que "a criança é cearense, não importa onde ela nasceu ou estuda" tem o direito à aprendizagem (CRUZ, 2017, p. 208).

Em 2013, a Secretaria iniciou uma ação focada naqueles que não se alfabetizaram até o $3^{\circ}$ ano, com o Programa Luz do Saber - software que estimula, por meio de jogos, as competências necessárias para aprendizagem da leitura e da escrita. A iniciativa visa contribuir para a alfabetização de crianças, além de promover a inserção na cultura digital ${ }^{7}$. Novas estratégias deveriam ser criadas para atuar em outros grupos específicos, como crianças com deficiência, indígenas, entre outros.

Ribeiro, Bonamino e Martinic (2020) fazem uso do conceito de instrumentos, técnicas e ferramentas de Lascoumes e Les Galès (2005) para explicar várias das estratégias do Paic: o Programa teria, para esses autores, adotado um conjunto de instrumentos que cumprem o papel de colocar os agentes implementadores em torno de objetivos comuns, conforme teorizaram os sociológicos franceses. Constituem-se em medidas destinadas a instituir vigilância do sistema sobre as interações e práticas dos profissionais da educação e a conduzir as ações dos dirigentes municipais, que tornaram o comportamento desses atores "orientado" para os objetivos previstos. Trata-se de um modelo que conduz experimentações de governança visando o que os gestores nominam de melhoria da qualidade da educação, sendo que essa noção de qualidade se mostra vinculada a padrões que indicam os termos da distribuição do conhecimento que é definido como relevante e também à perspectiva da promoção da equidade intraescolar e sistêmica. Dessa relação entre padrões e vigilância sobre as ações, surgem novas medidas educativas visando correções ou reenquadramento das interações e ações de agentes implementadores. Esse resultado converge com Crahay (2000) que trata de requisitos para o alcance da equidade na escola.

Ribeiro, Bonamino e Martinic (2020, p. 716) destacam também a relevância do aspecto simbólico introduzido por instrumentos de mediação das interações entre os entes federados no estado:

segundo os depoimentos, as ferramentas que orientam a divisão da quotaparte entre os municípios e o Prêmio Nota Dez implicam os prefeitos na

${ }^{7}$ A Secretaria realiza as capacitações e disponibiliza o software e materiais a todos os municípios. Entretanto, em 2018, 38 municípios participaram das três formações oferecidas. Os materiais e o software são disponibilizados no site da Secretaria e podem ser baixados por qualquer pessoa (CEARÁ, 2019b). 
implementação do Paic, levando-os a fortalecerem a capacidade de gestão das Secretarias de Educação. Para além do interesse por mais recursos financeiros, os prefeitos angariam, por meios simbólicos, nos eventos de premiação e decorrências, poder político junto a seus pares e eleitores.

\section{Considerações finais}

Este texto apresenta estratégias de gestão do Paic, programa concebido pelo governo do estado do Ceará e que, segundo pesquisas, tem ampliado a equidade educacional. Com a cooperação técnica e financeira aos municípios na implementação da educação pública, o estado busca promover a coordenação da política educacional entendendo que é seu papel apoiar a melhoria da educação, reduzir as desigualdades de acesso e garantir a qualidade do atendimento e a aprendizagem na idade certa a todas as crianças cearenses.

O Paic tem buscado manter uma coalizão, no estado do Ceará, pela universalização do acesso à educação com qualidade e pelo direito à aprendizagem na idade certa, de modo a garantir esses objetivos nas agendas governamentais estadual e municipais. Com a adoção de várias estratégias de formação, disponibilização de materiais, monitoramento e avaliação permanentes, o Paic busca assegurar um movimento constante de estratégias de intervenção na realidade educacional cearense.

A continuidade da experiência por 13 anos com o Chefe do Executivo apoiando os gestores da Seduc e induzindo as ações das equipes regionais, municipais e das escolas tem permitido avanços na implementação, bem como a incidência sobre a desigualdade educacional, melhorando os níveis de aprendizagem de todos os alunos e, ampliando assim, a equidade.

A existência de ações de melhoria da gestão municipal e das escolas; apoio à leitura; fornecimento de materiais didáticos, livros, instrumentos e ferramentas; formação continuada aos gestores e professores; monitoramento constante; avaliação externa; comunicação permanente com a sociedade e incentivos financeiros para os municípios e escolas aprimorarem o desempenho têm gerado bons resultados na aprendizagem de todos, inclusive dos mais pobres (COSTA; CARNOY, 2015; KASMIRSKI; GUSMÃO; RIBEIRO, 2017; VIEIRA; PLANK; VIDAL, 2019).

Destaque ao acompanhamento sistemático da equipe gestora em nível central e regional das equipes municipais, escolas e ações dos professores em sala de aula, com "escuta" das demandas dos diversos atores, transformando-as em ações. Os estudos apontam que esta vigilância permanente possibilita a identificação de conflitos e adequações frente às 
demandas que surgem o que pode ser parte dos fatores para a promoção da melhoria da equidade no Ceará (CRAHAY, 2000).

O estudo indica que os resultados alcançados por essa política podem estar também relacionados com o modo como se construiu a mobilização de variados atores no Estado, gerando senso de responsabilização; com a ação da Seduc junto aos municípios, pautada na busca da confiança mútua; com um sistema de acompanhamento e avaliação capaz de mostrar, com agilidade, os estágios de aprendizagem e os avanços alcançados; e com os instrumentos e ferramentas adotados, capazes de colocar os agentes implementadores em torno de objetivos comuns.

Outras pesquisas poderão contribuir para entender os instrumentos e estratégias utilizadas para promover a equidade em um estado pobre brasileiro.

AGRADECIMENTOS: As autoras agradecem à Coordenação de Aperfeiçoamento de Pessoal de Nível Superior - Brasil (Capes), código de financiamento 001, ao GV Pesquisa da Escola de Administração de Empresas de São Paulo da Fundação Getulio Vargas, à Fundação de Amparo à Pesquisa do Estado de S. Paulo (Processo Fapesp: 2018/11257-6), à Fundação Tide Setúbal e à equipe do Paic, do Instituto de Pesquisa e Estratégia Econômica do Ceará (Ipece), da UFC e outros atores entrevistados bem como todos os servidores anônimos que responderam os pedidos de informação.

\section{REFERÊNCIAS}

ABRUCIO, F. L.; SEGATTO, C. I.; PEREIRA, M. C. G. Regime de colaboração no Ceará: funcionamento, causas do sucesso e alternativas de disseminação do modelo. São Paulo: Instituto Natura, FGV, CEAPG, 2016.

ANUÁRIO Brasileiro da Educação Básica 2017. São Paulo: Todos pela Educação/Editora Moderna, 2017.

ARAÚJO, K. H.; LEITE, R. H.; ANDRIOLA, W. B. Prêmios para escolas e professores com base no desempenho acadêmico discente: a experiência do estado do Ceará (Brasil). Revista Linhas, Florianópolis, v. 20, n. 42, p. 303-325, jan./abr. 2019.

BOURDIEU, P.; PASSERON, J. A reprodução: elementos para uma teoria do sistema de ensino. Lisboa: Veja Universidade, 1975.

BROOKE, N.; SOARES, J. F. (org). Pesquisa em eficácia escolar: origens e trajetórias. Belo Horizonte: Editora da UFMG, 2008. 
CALDERÓN, A. I.; RAQUEL, B. M. G.; CABRAL, E. S. O Prêmio Escola nota 10: meritocracia e cooperação para a melhoria do desempenho escolar. Ensaio: aval. pol. públ. Educ., Rio de Janeiro, v. 23, n. 87, p. 517-540, jun. 2015.

CEARÁ (Estado). Secretaria da Educação. Regime de colaboração para a garantia do direito à aprendizagem: o Programa Alfabetização na Idade Certa (Paic) no Ceará. Fortaleza: Seduc, 2012.

CEARÁ (Estado). Secretaria da Educação. Mais Paic. Histórico. História. Portal Mais Paic, 2016a. Disponível em: http://www.paic.seduc.ce.gov.br/index.php/o-paic/historico/historia. Acesso em: 24 mar. 2019.

CEARÁ (Estado). Secretaria da Educação. Mais Paic. Objetivos. História do Mais Paic. Portal Mais Paic, 2016b. Disponível em: http://www.paic.seduc.ce.gov.br/index.php/opaic/objetivos-e-competencia. Acesso em: 24 mar. 2019.

CEARÁ (Estado). Secretaria da Educação. Mais Paic. Eixos do Programa. Eixo gestão municipal. Portal Mais Paic, 2016c. Disponível em:

http://www.paic.seduc.ce.gov.br/index.php/o-paic/eixos-do-programa/eixo-de-gestao. Acesso em: 24 mar. 2019.

CEARÁ (Estado). Secretaria da Educação. Mais Paic. Eixos do Programa. Eixo ensino fundamental I. Portal Mais Paic, 2016d. Disponível em:

http://www.paic.seduc.ce.gov.br/index.php/o-paic/eixos-do-programa/eixo-de-alfabetizacao. Acesso em: 24 mar. 2019.

CEARÁ (Estado). Secretaria da Educação. Mais Paic. Eixo de educação infantil. Portal Mais Paic, 2016e. Disponível em: http://www.paic.seduc.ce.gov.br/index.php/o-paic/eixos-doprograma/eixo-de-educacao-infantil. Acesso em: 2 abr. 2016.

CEARÁ (Estado). Secretaria da Educação. Mais Paic. Eixos do Programa. Eixo ensino fundamental II. Portal Mais Paic, 2016f. Disponível em:

http://www.paic.seduc.ce.gov.br/index.php/o-paic/eixos-do-programa/eixo-de-alfabetizacao. Acesso em: 1 abr. 2019.

CEARÁ (Estado). Secretaria da Educação. Mais Paic. Eixo literatura e formação do leitor. Portal Mais Paic, 2016g. Disponível em: http://www.paic.seduc.ce.gov.br/index.php/opaic/eixos-do-programa/eixo-deliteratura-infantil-e-formacao-de-leitores. Acesso em: 2 abril 2016.

CEARÁ (Estado). Secretaria da Educação. Mais Paic. Eixos do Programa. Eixo de avaliação externa. Portal Mais Paic, 2016h. Disponível em:

http://www.paic.seduc.ce.gov.br/index.php/o-paic/eixos-do-programa/eixo-de-alfabetizacao. Acesso em: $1^{\circ}$ abr. 2019.

CEARÁ (Estado). Secretaria da Educação. Spaece 2016. Boletim do Gestor Escolar, Juiz de Fora (UFJF), v. 2, jan./dez. 2016. 
CEARÁ (Estado). Paic - Resultados. Mapas dos resultados. Portal Mais Paic, 2018. Disponível em: http://www.paic.seduc.ce.gov.br/index.php/resultados/mapas-dos-resultados. Acesso em: 5 abr. 2019.

CEARÁ (Estado). Portal da transparência, 2019a. Disponível em:

https://cearatransparente.ce.gov.br/portal-da-transparencia/servidores?locale=pt-BR\&__ Acesso em: 9 abr. 2019.

CEARÁ (Estado). Secretaria da Educação. Célula de Fortalecimento da Alfabetização e Ensino Fundamental. [Mensagem pessoal]. Mensagem recebida por carminhameirelles@gmail.com em 15 maio 2019b.

CODES, A. et al. Lições de experiências exitosas para melhorar a educação em regiões com baixos índices de desenvolvimento. Relatório Institucional. Brasília: Ipea, 2018.

COLEMAN, J. S. et al. Equality of educational opportunity. Whashington: Office of Education/US Department of Health, Education, and Wefare, 1966.

COSTA, L. O.; CARNOY, M. The effectiveness of an early-grade literacy intervention on the cognitive achievement of Brazilian students. Educational Evaluation and Policy Analysis, v. 37, n. 4, p. 567-590, 2015.

CRAHAY, M. L'école peut-elle-être juste e efficace? De l'égalité des chances à l'égalité des acquis. Belgique: De Boeck, 2000.

CRUZ, M. C. M. T. Implementação da política de creches nos municípios brasileiros após 1988: avanços e desafios nas relações intergovernamentais e intersetoriais. 2017. Tese (Doutorado) - Fundação Getulio Vargas, São Paulo, 2017.

CRUZ, M. C. M. T. Programa Aprendizagem na Idade Certa (Mais Paic): avanços permanentes na busca da equidade. São Paulo: Fundação Tide Setubal, 2019.

DUBET, F. Les dilemmes de la justice. In: DEROUET, J. C.; DEROUET-BESSON, M. C. Repenser la justice dans le domaine de l'éducation et de la formation. Lyon: Peter Lang, 2009. p. 29-46.

GUSMÃO, J. B.; RIBEIRO, V. M. Colaboração entre estado e municípios para a alfabetização de crianças na idade certa no Ceará. Cadernos Cenpec, São Paulo, v. 1, n. 1, p. 9-34, dez. 2011.

IBGE. Panorama. Brasil. Ceará. Brasília: IBGE, 2019. Disponível em: https://cidades.ibge.gov.br/brasil/ce/panorama. Acesso em: 7 abr. 2020.

INEP. Vencendo o desafio da aprendizagem nas séries iniciais: a experiência de Sobral/CE. Brasília: Inep, 2005. 171 p. (Série Projeto Boas Práticas na Educação, n. 1)

INEP. Sistema de Avaliação da Educação Básica. Avaliação Nacional da Alfabetização. Edição 2016. Brasília: Inep, out. 2017. Disponível em:

http://portal.mec.gov.br/index.php?option=com_docman\&view $=$ download\&alias $=75181$ - 
resultados-ana-2016-pdf\&category_slug=outubro-2017-pdf\&Itemid=30192. Acesso em: 9 abr. 2019.

INEP. Ideb - resultados e metas. Brasília: Inep, 2018. Disponível em: http://ideb.inep.gov.br/. Acesso em: 3 fev. 2019.

IPEA. Radar IDHM: evolução do IDHM e de seus índices componentes no período de 2012 a 2017. Brasília: IPEA; PNUD; FJP, 2019.

IPECE. Ceará - Estatística. Ceará em números. Fortaleza, 2015.

IPECE. Indicadores sociais do Ceará - 2017. Fortaleza: Ipece, 2018.

KASMIRSKI, P.; GUSMÃO, J.; RIBEIRO, V. O Paic e a equidade nas escolas de ensino fundamental cearenses. Est. Aval. Educ., São Paulo, p. 1-25, set. 2017.

KINGDON, J. W. Agendas, alternatives, and public policies. Nova York: Harper Collins, 1995.

NASPOLINI, A. A reforma da educação básica no Ceará. Estudos Avançados, São Paulo, v. 15, n. 42, p. 169-186, 2001.

PADILHA, F.; BATISTA, A. A. G. Evolução dos indicadores educacionais no Ceará: os anos finais do ensino fundamental. São Paulo: Cenpec, 2013. (Informe de Pesquisa, n. 4)

PADILHA, F. et al. Qualidade e equidade no ensino fundamental público do Ceará.

Cadernos Cenpec Nova série, São Paulo, v. 3, n. 1, dez. 2013. Disponível em:

http://cadernos.cenpec.org.br/cadernos/index.php/cadernos/article/view/215. Acesso em: 5 jul. 2020.

PNUD; FUNDAÇÃO JOÃO PINHEIRO; IPEA. Atlas Brasil 2013 - consulta. Brasília: Pnud, Fundação João Pinheiro, Ipea, 2013.

QEDU. Portal. Disponível em: https://www.qedu.org.br/. Acesso em: 25 mar. 2019.

RIBEIRO, V. M. Que princípio de justiça para a Educação Básica? Cadernos de Pesquisa, São Paulo, v. 44, n. 154, p. 1094-1109, out./dez. 2014.

RIBEIRO, V. M.; BONAMINO, A.; MARTINIC, S. Implementação de políticas educacionais e equidade: regulação e mediação. Cadernos de Pesquisa, São Paulo, v. 50, n. 177, p. 698-717, jul./set. 2020.

SEGATTO, C. I. O papel dos governos estaduais nas políticas municipais de educação: uma análise dos modelos de cooperação intergovernamental. 2015. Tese (Doutorado) Fundação Getúlio Vargas, São Paulo, 2015.

SPAECE. O sistema. Portal do Spaece, 2018. Juiz de Fora: Caed; UFJF, 2018. Disponível em: http://www.spaece.caedufjf.net/o-sistema/o-spaece/. Acesso em: 10 abr. 2018. 
SUMIYA, L. A. Sobral e a garantia da aprendizagem de todas as crianças. São Paulo: Fundação Tide Setubal, 2019.

VIEIRA, S. L.; VIDAL, E. M. Construindo uma história de colaboração na educação: a experiência do Ceará. Educação \& Sociedade, Campinas, v. 34, n. 125, p. 1075-1093, 2013.

VIEIRA, S. L.; PLANK, D. N.; VIDAL, E. M. Política Educacional no Ceará: processos estratégicos. Educ. Real., Porto Alegre, v. 44, n. 4, 2019. Disponível em:

http://www.scielo.br/scielo.php?script=sci_arttext\&pid=S2175-

$62362019000400603 \& \operatorname{lng}=e n \& n r m=$ iso. Acesso em: 18 jan. 2020.

\section{Como referenciar este artigo}

CRUZ, M. C. M. T.; FARAH, M. F. S.; RIBEIRO, V. M. Estratégias de gestão da educação e equidade: o caso do programa aprendizagem na idade certa (mais PAIC). Revista on line de Política e Gestão Educacional, Araraquara, v. 24, n. 3, p. 1286-1311, set./dez. 2020. eISSN:1519-9029. DOI: https://doi.org/10.22633/rpge.v24i3.13904

Submetido em: 06/04/2020

Aprovado em: 20/07/2020

Publicado em: 01/09/2020 